NOVAS FORMAS

\title{
ASSOCIATIVAS NA PRODUÇÃO RECENTE DE MORADIA SOCIAL NO BRASIL
}

\author{
Camila Moreno de Camargo
}

\begin{abstract}
R E S U M O O presente artigo aborda aspectos relacionados à produção habitacional da modalidade "Entidades" do programa Minha Casa Minha Vida, a partir de observaçóes de campo. Pretende-se elaborar uma chave de leitura que destaque, no contexto de atendimento do programa federal mencionado, as entidades organizadoras e os diferentes graus de vinculação e relação que estabelecem com os movimentos de luta por moradias nacionais, a sociedade e o próprio Estado. Tais questôes vêm se construindo e nos mostram certa urgência de análise e pesquisas mais aprofundadas, no sentido de avançar na discussão acerca da produção habitacional por meio da autogestão no Brasil, visto que, ainda que inexpressivo do ponto de vista quantitativo e em comparação com a produção mais massiva empreendida pelo mercado, ela nos revela uma série de transformaçóes que vem redefinindo as relaçóes sociais e a produção do espaço urbano contemporâneo.
\end{abstract}

P A L A V R A S - C H A V E : Habitação de interesse social; Minha Casa Minha Vida; Entidades; Movimentos Sociais; Politica habitacional.

No ano de 2009, em resposta à crise econômica mundial, o Governo Federal lançou o programa habitacional Minha Casa Minha Vida (MCMV), com o objetivo de produzir um milhão de casas no país. Atualmente, em sua segunda fase, o programa tem como meta a produção de mais dois milhôes de unidades no território nacional.

Visando aquecer a economia através de estímulos às atividades da construção civil no país, pelo reconhecimento do seu potencial "anticíclico", o MCMV foi moldado para atender a promoção pública habitacional, mas sobretudo o segmento econômico popular de mercado. Essa produçáo se dá por meio de parcerias entre agentes diversos, passando pelas três esferas governamentais, empresas construtoras e, em uma modalidade específica do programa, entidades organizadoras sem fins lucrativos.

Tal produção enseja toda uma reflexão sobre as relaçôes institucionais e políticas entre esferas de governo; entre governo e construtoras; entre governo, construtoras e entidades organizadoras; e entre esses agentes e os beneficiários do referido programa, os futuros usuários do produto habitacional e urbano.

O presente artigo se dá a partir do apontamento de algumas questóes que surgem de nossa pesquisa de doutorado, que se encontra em andamento, e também de nossa participação em pesquisa coordenada pela professora Cibele Rizek através do LEAUC - Laboratório de Estudos do Ambiente Urbano Contemporâneo (grupo de 
pesquisa vinculado ao Instituto de Arquitetura e Urbanismo da USP) - e da assessoria técnica Peabiru - trabalhos comunitários, que apresentam como objeto de estudo a modalidade "Entidades" do programa MCMV, exatamente porque é nela que se pode apreender mediadores e operadores, bem como resquícios, permanências e redefiniçóes de entidades populares provenientes dos movimentos de moradia, que tiveram papel fundamental na reivindicação do "direito à cidade" e de uma política habitacional voltada aos mais pobres.

A realização dessa investigação parte de dois casos específicos e emblemáticos, definidos em decorrência de pesquisa de campo de caráter exploratório feita a partir do universo de contrataçóes realizadas por essa modalidade do programa entre os anos de 2009 e 2012, por revelarem uma série de questôes que contribuem para a compreensão das formas recentes de produção de moradia. Pretende-se promover uma abordagem transversal que perpasse questôes do processo - acesso das famílias e das entidades ao programa e ao financiamento, mobilização das famílias pelas entidades, gestão dos empreendimentos - e do produto habitacional - inserção urbana, tipologias habitacionais, qualidade construtiva, para contribuir com as investigaçóes recentes acerca da financeirização habitacional e urbana.

Assim, considerando o quadro das políticas sociais do Brasil contemporâneo, especificamente nos governos Lula e Dilma Rousseff, para o presente artigo, pretende-se elaborar uma chave de leitura que destaque, no contexto de atendimento do programa federal mencionado, as entidades organizadoras e os diferentes graus de vinculação e relação que estabelecem com os movimentos de luta por moradia nacionais, a sociedade e o próprio Estado, na composição da demanda e na atuação local.

Destaca-se que, ainda que inexpressivo do ponto de vista quantitativo e em comparaçáo com a produçáo mais massiva empreendida pelo mercado, essas experiências nos revelam uma série de transformaçóes que vêm redefinindo as relaçóes sociais e a produção do espaço urbano contemporâneo.

\section{NOVAS CHAVES DE LEITURA SOBRE AS CIDADES BRASILEIRAS}

Na passagem dos anos 1970 para os anos 1980, diante de um contexto de piora das carências urbanas, novos atores - os movimentos sociais urbanos - despontarão no cenário urbano e social tornando visíveis as desigualdades de condição de vida, marcas das cidades regidas pela modernizaçáo conservadora, que operava a partir de um Estado fortemente centralizado e pesadamente autoritário.

Por um lado, constatava-se que, ao contrário das expectativas anteriores, as camadas pobres das grandes cidades provavelmente não poderiam ser pensadas como alvos futuros de uma integração que associasse indústria, assalariamento e melhores condiçôes de vida, já que a ditadura empreendia políticas de expansão industrial, acompanhada de margens significativas de arrocho salarial e de processos repressivos que obstaculizavam a organizaçáo sindical e política dos trabalhadores. Por outro, no final da década de 1970 e meados da de 1980, com os movimentos sindicais e manifestaçóes de apoio às greves do $\mathrm{ABC}$ paulista, novos temas e novas questóes tomavam corpo: tratava-se do contraponto entre Estado e sociedade civil acompanhado de mapeamentos fortemente ideologizados (SINGER; BRANT, 1981). 
A ideia de virtude (OLIVEIRA, 2006) associada aos movimentos sociais e às formas mais ou menos populares de organização, enquanto lugar da ação política e dos processos e anseios de democratização, permitia desnaturalizar e problematizar as desigualdades e seu desenho urbano. O Estado e seu caráter autoritário, centralizado, burocratizado ganhavam o sinal contrário: lugar dos circuitos viciosos; sujeito de um conjunto de equívocos que era preciso identificar e combater; instituinte de um conjunto de empresas que desenhavam um setor produtivo estatal crescentemente autonomizado, em que se entrelaçavam favores, grupos e capitais, fora de qualquer controle social. Nesse quadro, uma das mais importantes chaves de leitura da cidade brasileira e de seus processos de constituição, devidamente politizados (no contraponto à questão e dimensão técnicas, por exemplo, ou mesmo simplesmente sociais) foi constituída a partir dos movimentos sociais - novos personagens que entravam em cena, como queria Eder Sader (1990) ou mesmo sujeitos coletivos de novo tipo que reconfiguravam o presente e o passado à luz da ideia de "protagonismo" da sociedade civil.

As novas pautas propostas atrelavam a produção da cidade e sua politização à visibilidade e à compreensáo de uma mistura heterogênea de atores e de mobilizaçóes - mulheres pobres, comunidades de base, movimentos de moradia, ocupaçóes de parcelas de terra pelas periferias, experiências de autogestão, assessorias técnicas devidamente politizadas, igrejas e correntes religiosas, movimentos de favelados, ao lado de movimentos e formas de organização sindical e política reconfigurados.

Nesse contexto, mesmo que a classe operária, ou classe trabalhadora, cedesse lugar para "as classes populares", a dinâmica das classes nas lutas pela cidade era, ao mesmo tempo, indicadora de leitura e modo de compreensão das formas urbanas de sociabilidade (PAOLI; SADER; TELLES, 1984). Tratava-se, então, de ler e compreender quem eram os trabalhadores urbanos para além das situaçóes de silenciamento e de cooptação - como no caso dos sindicatos, por exemplo, alargando em muito a leitura e a compreensão do que era a cidade como modo de existência. ${ }^{1}$

Assim, duas concepçóes ganhavam centralidade: a ideia de sociedade civil e as classes, não como lugares vazios, mas como experiência da exploração, da cidade, do conflito. Essas duas dimensôes, devidamente recobertas pela concepção de sujeitos históricos, foram transformadas em sedes das virtudes políticas e de processos de politização da questáo urbana, cada vez mais permeável à discussão da democratização da sociedade brasileira. Com base nesse novo cenário social e político, na contramão da década perdida, do ponto de vista econômico, tendo como eixo um novo patamar de legitimação dos conflitos sociais e urbanos, outro tema se desenha fortemente: a questão dos espaços e esfera públicos e a leitura da cidade, dos movimentos sociais, das linhas de força que permeavam as conformaçóes urbanas.

A cidade como espaço público ou como lugar da esfera pública - topos da política enraizada nas formas de apropriação de espaços e tempos, de processos cotidianos, de lutas e conflitos - aparecia como uma das bases de reflexão para a chamada elaboração cidadá, para os temas de uma cidadania incompleta, truncada e dilacerada que buscava se recompor pela e na luta pela redemocratização, pela e na luta pela Reforma Urbana, cujo horizonte foi o que ganhou as ruas como o que se entendia, de forma bastante livre como $o$ direito à cidade. Da periferia aos centros urbanos, a questão da cidade passa por novas configuraçóes.

Se os anos 1980 trouxeram grandes transformações nas práticas e concepções que nortearam a leitura das cidades, inclusive do ponto de vista da crítica às formas centralizadas
1 A ideia está presente em "São Paulo 1975 - Crescimento e Pobreza", mas pode ser encontrada em outros momentos da produção de Lúcio Kowarick. Ver Camargo et al. (1975). 
de intervenção urbana e produção de habitação social, os anos 1990 seriam marcados por um primeiro esvaziamento da legitimidade, do protagonismo e da centralidade dos movimentos sociais como atores e como chave de leitura da cidade. Neles se localiza uma primeira crise das representaçóes clássicas. Se na década de 1980 a chave dos movimentos, da autonomia da sociedade civil e das lutas democráticas colocava em primeiro plano a ideia de luta pela cidadania - e a bandeira do direito à cidade, tantas vezes empunhada pelo movimento nacional pela Reforma Urbana, foi uma das linhas mestras dessa reflexão -, a década seguinte seria marcada pela institucionalização da democracia formal, pelas múltiplas experiências de democracia participativa principalmente no âmbito municipal e pelo declinar das esperanças nas virtudes dos "encontros entre sociedade civil e Estado" (DAGNINO, 2002). Essas virtudes foram devidamente transformadas em confluência perversa entre o suposto protagonismo da sociedade civil e a desresponsabilização do Estado, em relação ao que se configurou como "a questão social brasileira" espacializada na cidade e na metrópole (DAGNINO, 2002).

Entre os anos 1990 e a primeira década do século XXI, um leque de novos temas e novas questóes conformaria os modos de leitura da cidade brasileira, bem como seu afastamento da questão social na sua face urbana. Ganhava corpo os temas da governança e governabilidade, fortemente inspiradas na chamada governança corporativa; das políticas sociais e políticas urbanas - sob a denominação de políticas públicas; da dinâmica pendular Estado e mercado, a partir da ideia das parcerias tanto em relação aos processos de intervenção quanto em relação à filantropização e refilantropização da pobreza; da financeirização, globalização e grandes projetos de intervenção urbana; da fragmentação urbana e do fim da ideia de totalidade; novas formas de "combate à pobreza" por meio de um conjunto de programas sociais que recobrem os territórios da precariedade; políticas públicas de "inclusão", de renda, de geração de emprego, de cultura que reconfiguram territórios e constituem atores, redes e institucionalidades; e, finalmente, o tema das violências e dos ilegalismos, em suas múltiplas formas e expressōes na cidade (OLIVEIRA; RIZEK, 2007).

Lembrando a expressão weberiana relativa ao paradoxo das consequências, as duas últimas décadas viram nascer a passagem do protagonismo da sociedade civil para a nova gestâo, administração e pacificação da pobreza, no avesso da legitimidade dos conflitos e da construção da questáo da desigualdade como questáo social. Assim também o lugar e o papel do Estado - marcado por uma dinâmica concebida como pendular em relação à sociedade civil e ao mercado - se transformariam, passando a ser concebidos como fronteiras atravessadas por um emaranhado que borrou distinçóes clássicas e suas polarizaçôes.

Talvez ainda seja necessário indagar de que modo se transformaram, se "rotinizaram" e se adaptaram às experiências inovadoras dos anos 1980, destruindo suas dimensôes políticas, para uma nova roupagem técnica - isto é, transformando as práticas, os núcleos associativos e os processos de politização das dimensôes urbanas em tecnologias sociais e de gestão, em empresariamento e autoempresariamento, em empreendedorismo social ou não. Assim, por exemplo, pode-se perseguir os recentes estudos acerca das assessorias técnicas aos movimentos sociais pouco a pouco transformadas em ONGs, OSs e OSCIPs e, posteriormente, substituídas ou transformadas em grandes empresas de gestáo das questôes sociais relativas à habitação e/ou urbanizaçáo de favelas, ou mesmo gestáo social e/ou técnica que se transforma em condicionalidades ou pré-requisitos da produçáo de infraestrutura urbana. 
A partir do final dos anos 1990, uma parte das experiências de produção da cidade para as classes populares foi absorvida como programas institucionalizados pelo Estado brasileiro, que passaram a ser vistos sob a chave da "habitação de interesse social”. De lideranças políticas na disputa pela cidade, esses atores passaram a ser vistos como "público alvo" de programas habitacionais. Por outro lado, na primeira década deste século, outra parte dessas mesmas classes pôde ascender socialmente e engrossar a agora considerada "classe C" que, por sua vez, foi descoberta como um nicho promissor e lucrativo para o mercado imobiliário.

Se anteriormente a leitura da cidade poderia ser feita sob a chave do encontro entre sociedade civil e Estado, nos últimos anos ela tem que se haver com a confluência entre Estado e mercado - a que se soma mais recentemente o capital financeiro (PAULANI, 2008). Dessa confluência, derivaram-se tanto os grandes projetos urbanos em metrópoles brasileiras (sobretudo Sáo Paulo), na perspectiva de integraçáo ao mercado financeiro mundial (FIX, 2007; FERREIRA, 2007), como a produção de empreendimentos de espaços urbanos padronizados, privatizados, fechados e destinados para residências da "classe C" - que se espalharam pelo território nacional.

\section{DIMENSÕES DE UM CAMPO DE INVESTIGAÇÃO - CONSTRUINDO QUESTÕES}

Inseridos neste quadro, os movimentos de moradia e suas assessorias, entidades profissionais e organizaçóes do campo da reforma urbana formularam a proposta do Fundo Nacional de Moradia Popular (FNMP), em 1991, visando garantir investimentos para a moradia popular e viabilizar, no plano nacional, recursos permanentes para a autogestáo na habitação social. A criação do Sistema e do Fundo Nacional de Moradia Popular (SNHIS e FNHIS) será uma das principais bandeiras das Caravanas e Marchas organizadas pela União Nacional de Moradia Popular (UNMP), Movimento Nacional de Luta por Moradia (MNLM), Confederação Nacional de Associaçōes de Moradores (CONAM), Central de Movimentos Populares (CMP) e pelo próprio Fórum Nacional de Reforma Urbana (FNRU), durante todo o longo período entre a apresentaçáo do projeto de lei de iniciativa popular na Câmara (1991) e a data de sua aprovação, em 2005.

Durante esse período de "banho-maria", como incita Moreira (2009), vão ocorrer importantes experiências de produção habitacional envolvendo procedimentos autogestionários em âmbito local. Destaca-se a gestão municipal de Luiza Erundina em São Paulo, de 1989 a 1992, como caso paradigmático da concretização de certas propostas. Os movimentos de moradia queriam respostas rápidas e, sem poupar a gestão progressista, faziam pressão com atos e acampamentos, "atuando [...] como agentes impulsionadores e legitimadores do espaço que se abria na HABI/SEHAB com o FUNACOM"2 (FELIPE, 1997, p. 42). A proposta de produção habitacional por meio da autogestão foi incorporada gradualmente enquanto linha de ação da Superintendência de Habitação Popular (HABI), com certa resistência dentro da própria Secretaria de Habitação, inicialmente sugerindo apenas o caráter experimental à proposta.

Ainda assim, havia expectativa que o processo de organização autogestionária dos indivíduos em torno da produção de sua própria moradia ensaiaria formas superiores
20 FUNAPS foi criado em 1979 para viabilizar à PMSP uma atuação independente do SFH, e seus recursos poderiam ser destinados, a fundo perdido, para o atendimento de famílias com até quatro salários mínimos moradoras de habitações precárias. Ver Ronconi (1995), Felipe (1997), Carvalho (2004), Baravelli (2006). 
novas até mesmo de organização social da cidade: "[...] falava-se, por exemplo, que a organização das classes populares em torno de um determinado processo autônomo de gestão produtiva e reprodutiva de segmentos urbanos promoveriam, a médio prazo, 'áreas libertas' da cidade" (LOPES, 2006).

Mais do que isso, que a politização do ato de construir, a possibilidade de gerir pelo menos um dos aspectos da produçáo material da vida, poderia instituir uma evoluçáo em cadeia, estendendo a consciência do autor que decide sobre si mesmo e realiza sua própria história para os outros âmbitos da existência. Além disso, a alteração das formas de organização do trabalho no canteiro promoveria não só transformaçôes no objeto casa - por meio de projetos decididos no diálogo participativo entre profissionais e usuários, materiais aplicados de qualidade superior, composiçóes urbanísticas e arquitetônicas mais cuidadas etc. -, mas também estabeleceria outro patamar de interlocução profissional. Uma forma de questionar a ação pública e do mercado no que tangia à produção de habitação de interesse social.

Será diante desse quadro de reivindicaçôes que, em 2004, no bojo da aprovação do Plano Nacional de Habitação e do FNHIS, que serão construídos três programas de Habitação de Interesse Social, voltados para a autogestão. O primeiro, o Programa Crédito Solidário (PCS), lançado em 2004, utilizou recursos do Fundo de Desenvolvimento Social (FDS). Foi pioneiro ao gerar novas demandas para a Caixa Econômica Federal, agente operador acostumado a trabalhar apenas com construtoras. O segundo programa idealizado foi a Ação de Produção Social da Moradia (APSM), lançada em 2008 após a modificação da Lei do SNHIS (através da Lei no 11.578/2007), que garantia o acesso das associaçóes e cooperativas ao FNHIS. Por último, o terceiro programa, lançado em 2009, foi o Programa Minha Casa Minha Vida Entidades, que hoje é o principal programa a incorporar a autogestão em seus processos produtivos.

Os apontamentos a seguir surgem de uma primeira fase do trabalho de campo das investigaçóes mencionadas e que se deu junto a alguns estudos de caso representativos das produçóes dos estados de São Paulo, Rio de Janeiro, Rio Grande do Sul e Goiás. Para a construção desses campos primeiros de investigação, foram sistematizados e analisados dados relativos aos contratos firmados desde o lançamento do Programa Minha Casa Minha Vida Entidades, em 2009, até o final do ano de 2012, advindos do Ministério das Cidades/ Secretaria Nacional de Habitação, Caixa Econômica Federal e registros obtidos junto às entidades organizadoras envolvidas e movimentos sociais. $\mathrm{O}$ aprofundamento de algumas hipóteses que se delineiam estáo se dando a partir de pesquisa de campo de caráter etnográfico junto a dois estudos de caso presentes na Regiấo Metropolitana de São Paulo, a fim de "dar relevo" a um conjunto de questôes construídas, uma vez que a análise dos dados quantitativos oficiais não é reveladora do processo percorrido pelos atores envolvidos.

Sobre esse aspecto vale dizer que quando a contratação vira um número oficial já se passaram anos de negociaçóes entre a entidade e o proprietário do terreno, a demanda já foi composta e recomposta inúmeras vezes a assessoria técnica envolvida na elaboração do projeto urbanístico e arquitetônico, bem como no projeto técnicosocial, já foi incrivelmente desgastada e a relação com o poder público local, ou seja, o jogo de forças que irá se estabelecer em determinado momento com lideranças de bairro, partidárias ou ligadas aos movimentos sociais de moradia, também vai sofrendo alteraçôes na medida em que também se alteram os contextos políticos.

Os cancelamentos de contrato também ficam na invisibilidade. Somente 
comparando momentos distintos de sistematização dos dados podemos perceber que alguns contratos "sumiram" da planilha oficial. As causas dos cancelamentos não é indicada. Não é considerada informação a ser sistematizada, mas pode revelar inúmeras questôes importantes para a análise do programa e para seu desenho operacional, justamente por indicar seus gargalos, aquilo que "não é" e por isso mesmo "é". O que há por trás desses cancelamentos? São questôes ligadas ao processo, resultado da disputa de um campo de forças e que compóem o quadro da produção recente de moradia social.

Outra questão também merece destaque justamente por dizer respeito ao produto fim-cidade. Trata-se do porte real dos empreendimentos, da sua inserção urbana e do impacto gerado sobre o conjunto de serviços públicos e infraestrutura urbana. Alguns empreendimentos são fragmentados em três ou quatro contratos a fim de se viabilizarem burocraticamente, mas na verdade correspondem a um único grande empreendimento. É o que estamos identificando como contiguidade de contratos e que, em geral, irá se dar por um consórcio de entidades (o movimento de moradia "cria" entidades e distribui as demandas entre elas).

Para além das questôes relativas à localização predominantemente periférica dos empreendimentos, a manobra realizada através dos instrumentos urbanísticos presentes nos próprios Planos Diretores municipais, a esse "campo de disputa" pela compra da terra criado entre entidades e grandes empreiteiras, os aspectos produtivos - abordando os desenhos urbanos (parcelamento e implantação) e da unidade habitacional -, os processos construtivos, os tipos habitacionais, entre outros, destacam-se o papel desempenhado pelas entidades organizadoras e os diferentes graus de vinculação e relação que estas estabelecem com os movimentos de luta por moradia nacionais, a sociedade, o mercado e o próprio Estado, na composiçáo da demanda e na atuação local.

Em São Paulo, as entidades organizadoras, em geral, são vinculadas a um dos movimentos nacionais de luta por moradia - a UNMP. Na capital do estado, esse movimento organiza-se a partir dos bairros de atuação, por exemplo, a Uniáo dos Movimentos de Moradia (UMM) Zona Oeste. Serão nas sedes desses escritórios regionais que se darão o cadastro das famílias, a organização da documentação, as reunióes de avaliação de todo o processo, a elaboraçáo de cronograma de atividades e a rede de informes. A partir do mapeamento das demandas são criadas as entidades que irão solicitar a aprovação do projeto junto ao Programa MCMV Entidades, inclusive nas cidades no entorno, como Santo André (ABC paulista), Mauá, Suzano, entre outras.

Também é o movimento que articula a aquisiçáo do terreno, contrata o projeto arquitetônico, organiza as famílias em torno da construção, coordena os trabalhos de mutirão - quando é o caso - e acompanha o processo de aprovação na Caixa Econômica Federal (CEF). Desempenha um papel fundamental, que é o de permanente avaliação do programa, dos resultados obtidos e dos conflitos e entraves que se apresentam em meio ao processo, a partir do qual irão reivindicar alteraçóes nas normativas do programa junto ao Ministério das Cidades, dado seu histórico de lutas em torno do direito à cidade e ao acesso à moradia, que já mencionamos.

Cabe destacar que a UNMP foi criada em 1989 e que hoje atua em 19 estados brasileiros, sendo também responsável pela implementação desta modalidade do programa na Bahia, em alguns casos de Goiás, Minas Gerais, Maranhão, entre outros. Além disso, o movimento faz parte de uma rede latino-americana, a SELVIP 
3 Todos os trechos de depoimentos expostos no artigo foram coletados em entrevistas gravadas e transcritas pela pesquisadora e comporão sua tese de doutorado.
- Secretaria Latino-Americana de la Vivienda Popular -, que discute e reivindica a autogestão e a ajuda mútua (mutirão) na produção habitacional há mais de vinte anos. Ainda assim, apesar do nível de consciência política e de lutas envolvendo o direito à moradia, na prática observa-se que todo o processo acaba por girar em torno do produto-fim: a casa própria.

Em São Paulo, assim como no Rio de Janeiro, é marcante a presença das assessorias técnicas desde a elaboração e discussão sobre o projeto arquitetônico e urbanístico, como também no processo de construção e no desenvolvimento do trabalho técnico social, em geral a ela vinculada. No entanto, novas assessorias vêm ocupando esse espaço e estabelecendo outras formas de relaçáo com o movimento social e suas lutas. Assim, quando questionados pelo trabalho cada vez mais "profissionalizado" e qual o significado disso, a resposta foi bastante direta: "Graças a Deus eles optaram por contratar uma construtora para toda a obra (administraçáo indireta), já que eles não têm a menor experiência com mutirão [...] isso atrasaria demais a obra."”

Essa ideia de "profissionalização" também está presente no próprio movimento, cujas principais lideranças declararam "[estar] aprendendo muito com a Caixa Econômica Federal. [...] Agora, estamos produzindo unidades [habitacionais] iguais às do mercado". Além disso, a nivelação entre a produção de mercado e a produção vinculada às entidades também aparece na fala de representantes da Caixa Econômica Federal, que destaca que "a burocracia é a mesma. A documentação exigida para as entidades é exatamente a mesma exigida para as empresas, entáo náo sei por que eles reclamam tanto. Eles precisam e estão se profissionalizando. Estamos avançando em conjunto".

Além disso, é possível também encontrar uma série de indícios que permitem identificar e compreender deslizamentos e reconfiguraçôes das representaçôes e práticas desses movimentos, reconhecidas, por exemplo, no fato de importantes movimentos de moradia irem de antigas reivindicaçóes por moradia em áreas centrais à coordenação e gestão de empreendimentos do programa na periferia urbana de Sáo Paulo, ou então da atuação no campo da alfabetização de jovens e adultos à produção de moradia em mais de um estado brasileiro, na ideia de "expansáo dos negócios".

No Rio de Janeiro, em seu primeiro e, até agora, único caso de contrato firmado desde o Programa Crédito Solidário, também será a UNMP, o movimento que articula a entidade organizadora, a assessoria técnica e das famílias mutirantes. Há, aqui, a presença da universidade, através do IPPUR, que nos últimos anos vem ampliando suas análises nesse campo. Em São Paulo, a presença da universidade já não se faz mais tão presente e ficou evidente nas falas das lideranças certa "rusga" para com nomes de referência do urbanismo brasileiro, que sempre atuaram junto aos movimentos paulistanos, devido às recentes falas e críticas acerca do programa em questão e de seus resultados, principalmente no que tange à inserção urbana e a à qualidade projetual dos conjuntos.

No Rio Grande do Sul, nota-se a presença de três modalidades de entidades organizadoras: I) as cooperativas habitacionais ligadas ao MNLM e que há anos vêm reivindicando o direito à moradia. Para estas, o desafio presente é adequar-se às normativas e burocracias relacionadas ao programa e até mesmo à ideia de obtenção de escritura da casa própria, visto que sempre ficou em segundo plano; II) as "coopergatos" (termo utilizado pelas lideranças do MNLM), que dizem respeito às cooperativas criadas em função do programa e que apresentam funcionamento e lógica operacional 
similar ao de uma construtora, em menor escala; III) ONGs, igualmente criadas para se habilitar junto ao Ministério das Cidades, cujo funcionamento também se dá por meio de um "balcão de atendimento ao público". Em alguns casos, estáo sediadas junto a imobiliárias locais nas cidades em que atuam - visto que trata-se na verdade de "filiais" presentes em várias cidades.

Náo se faz muito presente à crítica ao programa, entendido como bom exclusivamente por ter recursos, o que em outros momentos da história não acontecia. Mas quando questionados sobre a diferença de investimento na produção empresarial e na produção ligada às entidades, "nós [o movimento] não estamos suficientemente organizados para canalizar os recursos do Minha Casa Minha Vida" e por isso "o movimento precisa se profissionalizar".

O debate em torno da localização dos empreendimentos fica centrado na dificuldade de aquisição de terrenos dado o desequilibrado campo de disputa estabelecido com o mercado imobiliário, que vai disputar as mesmas terras periféricas, porque são mais baratas, restando às entidades "a periferia da periferia". Nas falas dos futuros moradores, tanto em São Paulo como no Rio de Janeiro, observam-se certo conformismo com essa situação e a tentativa de se ressaltar os aspectos positivos do futuro local de moradia:

"Não me importo não. Tem um ônibus que passa aqui... demora pra chegar, mas hoje em dia qualquer lugar demora né!?. Olha que bonito é aqui! Olha quanto verde!"; "é muito tranquilo aqui. Não tem aquele barulho todo da cidade!"; “daqui a pouco as coisas vão melhorando, já tem uma vendinha ali na esquina."

Os desenhos dessas entidades são extremamente porosos. Os responsáveis pelas entidades, em certos casos, estão em cargos políticos ou são funcionários públicos, que irão "atender" a demanda a partir do próprio gabinete, ou então é a sede da entidade que vira o gabinete, estabelecendo relaçóes e vínculos muito pessoais com as famílias, envolvendo-se, na tentativa de apaziguar, por exemplo, casos de brigas familiares e tantos outros conflitos cotidianos.

Em outros casos, aparecem por trás das entidades, quando não assumem abertamente essa posição, ONGs estrangeiras ou então criadas por "grupos de empresários preocupados com o bem-estar da população brasileira”, que visam "à integração social e a criação de núcleos multiplicadores de conhecimento e articulação da sociedade civil" (descriçóes presentes no site de uma das entidades organizadoras responsável por dois contratos no Rio Grande do Sul) e que estabelecem horário de atendimento "normal" e horário de atendimento ao "associativismo".

Tais questôes vêm se construindo e nos mostram certa urgência de análise e pesquisas mais aprofundadas, no sentido de avançar na discussão acerca da produção habitacional por meio da autogestáo no Brasil, visto que, ainda que inexpressivo do ponto de vista quantitativo e em comparação com a produção mais massiva empreendida pelo mercado, ela nos revela uma série de transformaçóes que vem redefinindo as relaçóes sociais e a produção do espaço urbano contemporâneo.
Camila Moreno de Camargo é arquiteta urbanista, doutoranda pelo Instituto de Arquitetura e Urbanismo da Universidade de São Paulo (IAU-USP). Pesquisadora do LEAUC - Laboratório de Estudos do Ambiente Urbano Contemporâneo e do NAPUrb - Núcleo de Apoio à Pesquisa em Urbanização e Mundialização. E-mail: <cmcarq@hotmail.com>. 


\section{REFERÊNCIAS BIBLIOGRÁFICAS}

CAMARGO, Cândido P. Ferreira de. et al. São Paulo 1975: Crescimento e pobreza. São Paulo: Edições Loyola, 1975.

CARVALHO, Caio S. A. de. Lupa e telescópio: o mutirão em foco. São Paulo, anos 90 e atualidade. São Paulo: dissertação de mestrado FAUUSP, 2004.

PEABIRU. Gestão compartilhada e habitação social. Panorama e dificuldades na produção habitacional em parceria com organizaçôes populares - um olhar sobre o programa Crédito Solidário, de 2003 à atualidade. São Paulo: Peabiru TCA, 2010.

DAGNINO, Evelina. Sociedade Civil e Espaços públicos no Brasil. São Paulo: Paz e Terra, 2002. FERREIRA, Joáo S. W. (Coord.). Produzir casas ou construir cidades? Desafios para um novo Brasil urbano. Parâmetros de qualidade para a implementação de projetos habitacionais e urbanos. São Paulo: LabHab, FUPAM, 2012.

FERREIRA, João Sette Whitaker. $O$ mito da cidade-global: o papel da ideologia na produção do espaço urbano. Petrópolis: Vozes, 2007.

FIX, Mariana. São Paulo Cidade Global: fundamentos financeiros de uma miragem. São Paulo: Boitempo, 2007.

LOPES, João Marcos; RIZEK, Cibele. O mutirão autogerido como procedimento inovador na produção da moradia para os pobres: uma abordagem crítica. São Carlos: mimeo, 2005.

LOPES, João Marcos. O anão caolho. Novos Estudos, CEBRAP, n. 76, p. 219-227, nov. 2006.

MOREIRA, Fernanda. O lugar da autogestão no governo Lula. São Paulo: dissertação de mestrado FAUUSP, 2009.

OLIVEIRA, Francisco. Crítica à razão dualista: o ornitorrinco. São Paulo: Boitempo, 2003.

OLIVEIRA, Francisco de. O vício da virtude. Auto-construção e acumulação capitalista no Brasil. Novos estudos, CEBRAP, n. 74, p. 67-85, mar. 2006.

OLIVEIRA, Francisco de; RIZEK, Cibele Saliba (Orgs.). A era da indeterminação. São Paulo: Boitempo, 2007.

PAOLI, Maria Célia; SADER, Eder; TELLES, Vera da Silva. Pensando a Classe Operária: Os Trabalhadores Sujeitos ao Imaginário Acadêmico. Revista Brasileira de História, São Paulo, n. 3-6, p. 129-149, 1984.

PAULANI, Leda. Brasil delivery: servidão financeira e estado de emergência econômico. São Paulo: Boitempo, 2008.

RIZEK, Cibele. Os sentidos da cidade na sociologia brasileira. Relatório parcial do subprojeto 8 da pesquisa Cidadania e Democracia: O pensamento nas rupturas da política. Sáo Paulo, Fapesp, 2002.

RONCONI, Reginaldo. Habitaçóes construidas com gerenciamento pelos usuários, com organização da força de trabalho em regime de mutirão: o Programa FUNAPS Comunitário. Dissertação de Mestrado. São Carlos: EESC, 1995.

ROYER, Luciana. Política habitacional no estado de São Paulo: estudo sobre a Companhia de Desenvolvimento Habitacional e Urbano do estado de São Paulo. São Paulo: Dissertação de Mestrado, FAUUSP, 2002.

SADER, Eder. Quando novos personagens entram em cena. São Paulo: Paz e Terra, 1990.

SHIMBO, Lúcia Zanin. Habitação Social, Habitação de Mercado: a confluência entre Estado, empresas construtoras e capital financeiro. Tese (Doutorado em Arquitetura e Urbanismo) Escola de Engenharia de São Carlos, Universidade de São Paulo, São Carlos, 2010.

SINGER, Paul; BRANT, Vinícius Caldeira (Org.). São Paulo: o povo em movimento. Petrópolis: Editora Vozes, 1981.

TELLES, Vera. Nas dobras do legal e do ilegal: ilegalismos e jogos de poder nas tramas da cidade. Dilemas: Revista de Estudos de Conflito e Controle Social, v. 2, n. 5-6, p. 97-126, 2010. 
A B S T R A C T In response to the global economic crisis of 2009, the brazilian government launched the Minha Casa Minha Vida - MCMV program, with the purpose of producing one million houses in the country. In its second phase, currently the program aims to produce another two million housing in the country. This production occurs by means partnership among actors at the various political, commercial, social and voluntary levels. In this context, this article aims to develop a new key for reading the entities responsible for organising the construction of the project contracted and the different degrees of attachment and relationship they establish with the national fight for housing movements, the society and the state itself, in the composition of demand and performance location.

Such questions show some urgency in the analysis and further research for advancing in discussion about housing production through self-management in Brazil, it reveals a series of transformations that has been redefining social relations and production of contemporary urban space.

K E Y W O R D S social interest housing; "Minha Casa Minha Vida"; entities; social movements; housing policy. 